DE GRUYTER

OPEN

10.2478/cris-2014-0002

\title{
CHILDREN'S BOOK ILLUSTRATIONS: VISUAL LANGUAGE OF PICTURE BOOKS
}

HANA HLADÍKOVÁ

High-quality picture books that merge text and illustration together in order to tell a story are eminent for healthy mental and social growth of children. This paper is to outline the benefits picture books bring to children between the ages three to eight, determine functions of its illustrative language, examine the process of its production, and point out a set of elements that, according to number of professional children's book illustrators, significantly contribute to the success of a picture book. 


\section{APPEARANCE OF CHILDREN'S BOOKS AND THEIR BENEFITS TO CHILDREN}

Until relatively recently, there were very few books meant primarily for children to read. Children had to make do with literature that was not attuned to their level of understanding, neither in theme nor its language and vocabulary (Kiefer, 2009, p. 6). That changed in the late $19^{\text {th }}$ century. Thanks to new printing technology that made mass production of illustrated books possible and economically accessible, the middle class was also able to enter the world of readership. In addition to that, the attitude towards childhood was altered at that time, from almost solitary to more sentimental and respectful to its different needs, preparing a perfect ground for this new genre of picture books to grow in and flourish (Revolution21, 2013).

Contrarily to its generic categorisation as children's books, picture books entertain a wide spectrum of readers, and in many cases, even non-readers, from an early age through adulthood and beyond. Their power to inspire is wide. Picture books and their illustrations "can hook children into a lifelong love of reading" (Reading Is Fundamental, 2010). That is essential for their further development and their ability to perform well both in school and later in life, for the amount of information that each individual must cover in order to become successful in any line of career is now steadily increasing. For that reason, in many nations nowadays picture books are increasingly perceived as just an aged tool for encouraging children to start reading on their own, abandoning its other benefits in a race to get the children to read earlier and turn to chapter books as quickly as possible, in some cases skipping the stage of picture books entirely (Bosman, 2010; Sloat, 2013). It is due to pressure on both the parents' and industry's sides that are changing the traditional late Victorian view on the place of children's books in children's lives.

However, picture books have much more to offer. Firstly, its pictures introduce and explain the world to children in a comprehensive way even before they are able to read. It allows the children to get accustomed to new words and build up their vocabulary through both verbal and visual references provided by the book. Although a broad public generally believes differently, a vocabulary of picture books is usually very "rich, evocative and engaging" according to Pierce (2010). Many times its quality is much greater than language used in chapter books. The reason is in its average length allowing about five to eight hundred words. Because of that, "an author must craft each and every word, sentence and paragraph with care;" being exposed to such a quality of language aids significantly the growth of the children's language skills (Pierce, 2010).

Picture books also broaden general knowledge and enable children to get a better understanding of themselves and their integration within a society (Reading Is Fundamental, 2010). Its reach is as wide as its variety of themes. Picture books often trigger children's imaginations, which aid children to think of new ideas and bring new possibilities into their lives, both immediate and up-coming. Anita Silvey, for instance, states that many leading figures of the USA she has interviewed declared that their career choice was triggered by a children's book they read in their childhood (Library Of Congress, 2010).

Secondly, picture books require a certain amount of interaction from children; at the very least they have to turn the pages. This trains the child's concentration and can prolong its attention span. Another benefit is the development of the child's memory. Picture books are built in sequences that link pages together. The sequence is usually made of both visual and verbal elements and many times produces a certain pattern within the book. A great example of such a sequence is to be found in the book, Brown Bear, Brown Bear, What Do You See?, written by Bill Martin Jr. and illustrated by Eric Carle, where a great rhythm of rhymes introduces animals that are to appear on the next page (Pierce, 2010). 
The last, but not the least, reason to read picture books is perhaps the most important. Although the theme and purpose has changed repeatedly during the short life span of this genre, the majority of the most successful children's books are crafted to entertain, to pleasure, and to employ the child's imagination. It provides delight and entertainment that not only shows children that eventually it will be fun to become an active reader but also connects generations and people in general through the sharing of these engaging stories, experiences, and valuable time spent together. Anita Silvey claims that children's books are often attached to more than just their stories, amazing new worlds, or memorable characters; more importantly they are connected to the people the young reader knew and loved in his/her childhood (Library Of Congress, 2010). Sharing picture books with others provides children with feelings of love and security, feelings of utmost importance in their young age.

\section{PURPOSES OF ILLUSTRATION IN PICTURE BOOKS}

Illustration, as well as cover design, is one of the marketing tools a children's book publishing company employs to increase its chances in its highly competitive market. A picture book's artwork, both that on a cover and inside, creates a first and second impression on a potential reader and buyer and therefore is crucial for its sell ability. Tori Sloat (2013), however, adds that even though "illustrations may sell the book at the beginning ... to last a lifetime, the book has to begin to rely on the story and how it reads." This bond between the book's visual and written parts is a true key to its lasting success. To harvest this connection, the illustrator must follow the written word of an author, but also add his/her own personality, view, humour, and insight to the story.

The imperative role of illustrations within a picture book is to take the written story to a new level of entertainment. The artwork should stand for as much of the story as the words, expanding the story without duplicating the text itself while acting as a mediator between the text and the reader, allowing the reader "to feel the words" (Murguia, 2013; Downing, 2013; Sloat, 2013). Ann Marie Finn adds that she likes "to use illustrations to create more of an atmosphere ... and add another dimension to the story" (Finn, 2013). She also states that picture books' illustrations that are very often full of action and interesting additions to the story can lead to an extended attention span of children who are easily distracted otherwise. Another, perhaps more technical, purpose of illustrations is to set a seductive rhythm, hierarchy of elements on a page, and easy flow of the story while encouraging the reader through its layout and action depicted on its pages to keep enjoying the narrative until its end (Meidell, 2013).

\section{GETTING THE RIGHT BOOK INTO THE HANDS OF THE RIGHT ILLUSTRATOR}

Amongst the first factors in need of consideration in the process of producing artwork for an approved manuscript is the suitability of an illustrator and the narrative in terms of style and technique appropriate for the publication. Both of these influence the overall mood of the story greatly and can therefore contribute to the success or failure of the publication. Martin Ursell (2013, p. 96) states that "the author illustrator is a rare thing and most children's illustrators illustrate other writer's stories not their own." For that reason, it is imperative to select a fitting illustrator and determine the art director's expectations for the book at the very start so no misunderstanding imperils the smooth progression of the publishing process.

Christine Tripp argues that from a certain point of view, a style and a technique of illustrations for the particular book are in fact chosen by an art director's preference of an illustrator, for the majority illustrators have a recognisable "signature style", or even a variety of styles, from cartoonish to very realistic, using traditional media or working digitally instead (Tripp, 2013). Martin Ursell also mentions that many beginning 
illustrators ponder about "not having a style and how to get one", which he thinks to be a pointless worry (2013, p. 51). He says that "one's 'style' is simply the way one draws. Just as we all write in a distinctive way, drawing is no different" (Ursell, 2013, p. 51). In other words, there is no need to learn a distinguishing personal style of drawing, for everyone already has it. In case an illustrator uses a variety of styles, one is either selected by the art director when an offer is made to have a go on a manuscript, or, especially when the illustrator is also the author, the choice is left to the illustrator's judgement. The final decision is often linked to an overall mood and theme of the story. Tom Lichtenheld (2013, author's italics) gives an example of this practice, "if a story is soft and lyrical, I'll use watercolours or pastels, but if it's gritty, like Goodnight, Goodnight, Construction Site, I'll use crayon on textured paper."

In many cases, an art director preselects several illustrators whose personal styles are in tune with the manuscript and then asks them to produce sample illustrations. The sample can vary slightly according to different publisher houses, but usually it is a sample spread for a provided passage of the manuscript, which sometimes is extended with a more detailed study of the book's main character(s) (Ursell, 2013, p. 104). Then one of the illustrators is approached with an offer of the job. The final decision is, however, made by the artist by accepting or declining the job. Teri Sloat states that a few times she recommended the art director to hand the job over to another illustrator "because I knew they were right for the job and I wasn't" (2013). Also, Helen Craig points out that it "is not a good idea to illustrate a book you don't like, because there will be no pleasure in it. And if there is no pleasure in your drawing ... it transmits itself into the book" (Creative Choices, 2009). The illustrator spends a rather large amount of time working on a book, which can vary from a few months up to a year, and it would take much more discipline to finish the project, if the illustrator is not enthusiastic about the story itself (Teri Sloat, 2013; AlbanyKALB, 2013).

\section{ILLUSTRATING PROCESS}

The very first step the illustrator does after accepting the job is to familiarise oneself thoroughly with the whole manuscript. The story is a paramount source of illustrator's inspiration, and for that reason it is essential to pay due attention to its details that can trigger an interesting insight into the story, providing the illustrator with a good starting point. There are many ways how to bring the illustrations to life. Movement, both in body language, face, and settings together with the expressiveness of all the above, is as important as thorough consistency of the visual language of the whole book. Moreover, the emotional content of the story that is often communicated through the combination of composition, colour, line, or style can bring excitement, engagement, and something the reader can relate to, which makes the illustrations a very powerful part of the reader's experience. Originality of settings, choice of flat or dimensional images, and overall feeling of the narrative can also make a considerable impact on attracting and keeping the reader's attention in the story (Dewdney, 2013; Finn, 2013; Murguia, 2013; Lies, 2013; Tripp, 2013; Waites, 2013; Downing, 2013; Meidell, 2013; Sloat, 2013; Lichtenheld, 2013). It can be argued that many times it is a careful combination of these components that makes the illustrations special and dear to the reader, and each illustrator has a different way how to engage these elements and which elements he/she puts more emphasis on.

To point out an example, Teri Sloat (2013) states that she firstly considers "the weight of the story", which includes analysing the narrative's mood, theme, significance of characters, placement of the story, and its natural pace. Ann Dewdney (2013), however, claims that her "design process is based entirely on both the flow of the book and the emotional content of the pages". It is reasonable to conclude that whichever process the illustrator chooses to follow a consideration of these elements can assist the illustrator greatly in making important decisions such as the establishment of a balance between text and images, development of characters, overall layout, usage of white space, text division, colour scheme, or visual style. 


\section{RELATIONSHIP BETWEEN TEXT AND IMAGE}

A fine relationship between words and images is vital for picture books. Generally speaking, "what a picture adds to a story and what the words leave out, is key" (Revolution21, 2013). Both the author and the illustrator should have this fact in mind when working on the book. Ideally, the author is considerate to the needs of the illustrator and writes the text in a way that leaves enough room for the illustrator's creativity to enhance the author's creation. In other words, the author should be leading the reader through the action and leave the illustrator enough space to portray the mood of the story and details of the narrative's scenes and characters. This ensures that words and images are not to duplicate the statement of the story, but rather complement each other (Salisbury, 2004, pp. 93-97; Paul, 2009, p. 158; Dils, 2009, pp. 26-27). Therefore, one of the attributes of a successful picture book's illustration is often a complementary or parallel story line enhancing the original manuscript. A wonderful example of such practice is an addition of a cat character to the book Bears on the Stairs (Figure 1).

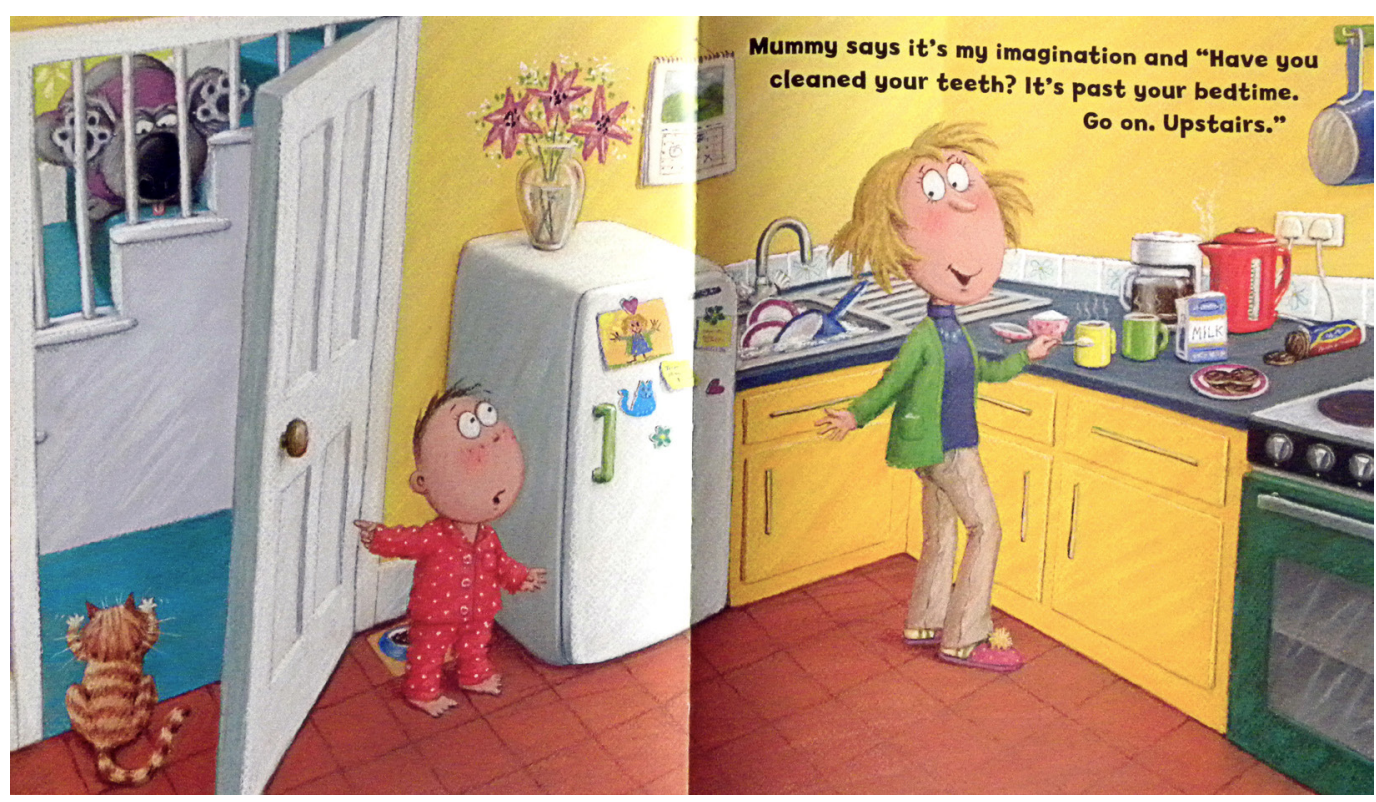

Fig. 1. Lynne Chapman, Bears on the Stairs, 2010

Even though it is not in the manuscript, the cat engages the reader in a whole new level by enhancing the story in a very clever way. It brings the opportunity of somewhat humorous interaction between the bears and the cat, reflecting the true feelings of the main character by proxy. It also enables the illustrator to subtly indicate places of higher interest on the page (Open College of the Arts, 2011).

However, the utmost responsibility of the illustrator is to maintain consistency of both verbal and visual communication levels of the book while enriching the story without contradicting the author's manuscript. To do so, many illustrators make a list of features and action that is encoded into the story already. Firstly, there is a certain level of action bond that should appear in the book. If the text portrays a busy character in a heap of action, the illustration should be complimentary in its mood. Nevertheless, there are some exceptions to this rule; for example, clever illustrations of Marla Frazee's picture book called A Couple of Boys Have the Best Week Ever, or Marta Altés's picture book No!. While Marta Frazee's illustrations use humour to contradict the text itself, which in the end adds a very special feeling to the book as a whole and make it rather enjoyable, Marta Altés's contradicting illustrations are based on presenting two different points of view to the reader, the human's and the dog's (Northurp, 2012, p. 2; Salisbury and Styles, 2012, pp. 108-110). 
Figure 2 and Figure 3 illustrate differences in both of these approaches and show rather well how the contradiction is applied to both stories. Marla Frazee challenges the reader's conception of the written truths by visual inversions. For example, when James (the boy in blue shorts) comes to visit Eamon's family, the text implies that he comes with just a couple of his belongings, while the image clearly shows an abundance of boxes and bags bursting with James' stuff. Later, the text indicates the boys' decision to stay home, while the illustration shows them running away so fast they each lost one of their shoes and little clouds of dust formed behind them.

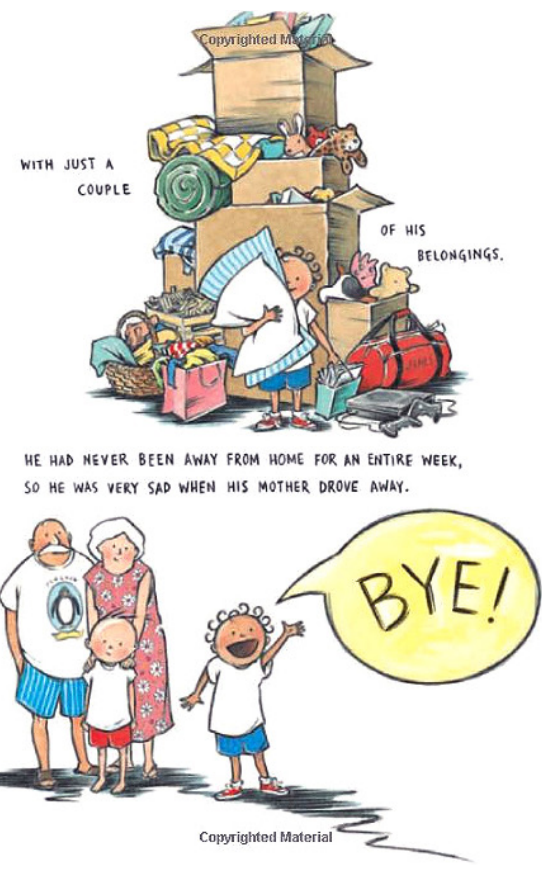

Copyrighted Material

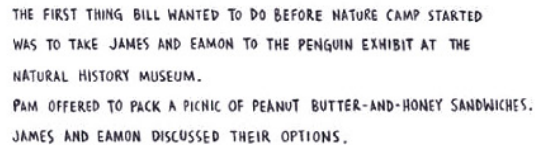

JMMES AND EAMON DISCUSSED THEIR OPTIONS.
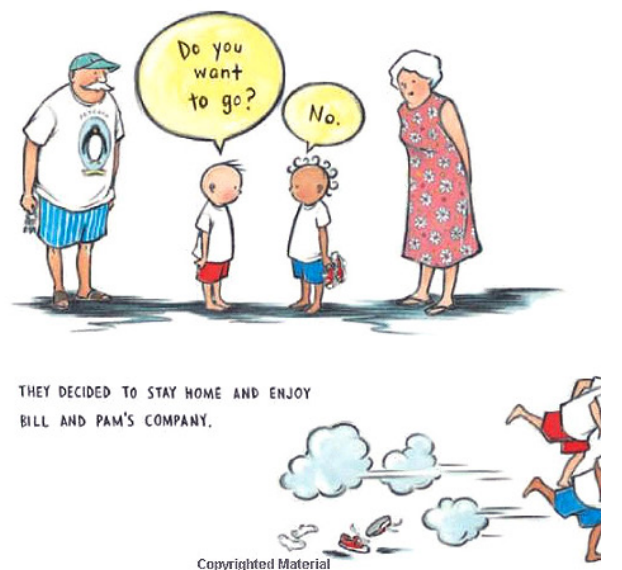

Fig.2. Marla Frazee, A Couple of Boys Have the Best Week Ever, 2008.

Marta Altés's approach is different. The textual and visual contradiction is based on the difference of a human's and a dog's conception of desirable and undesirable behaviour of a dog. While the dog assumes his family appreciates his frequent help with a variety of tasks and calls him No, the reader sees images of the same situations from a human point of view, seeing how the dog is being naughty while his family is trying to stop him by shouting 'no' at him.

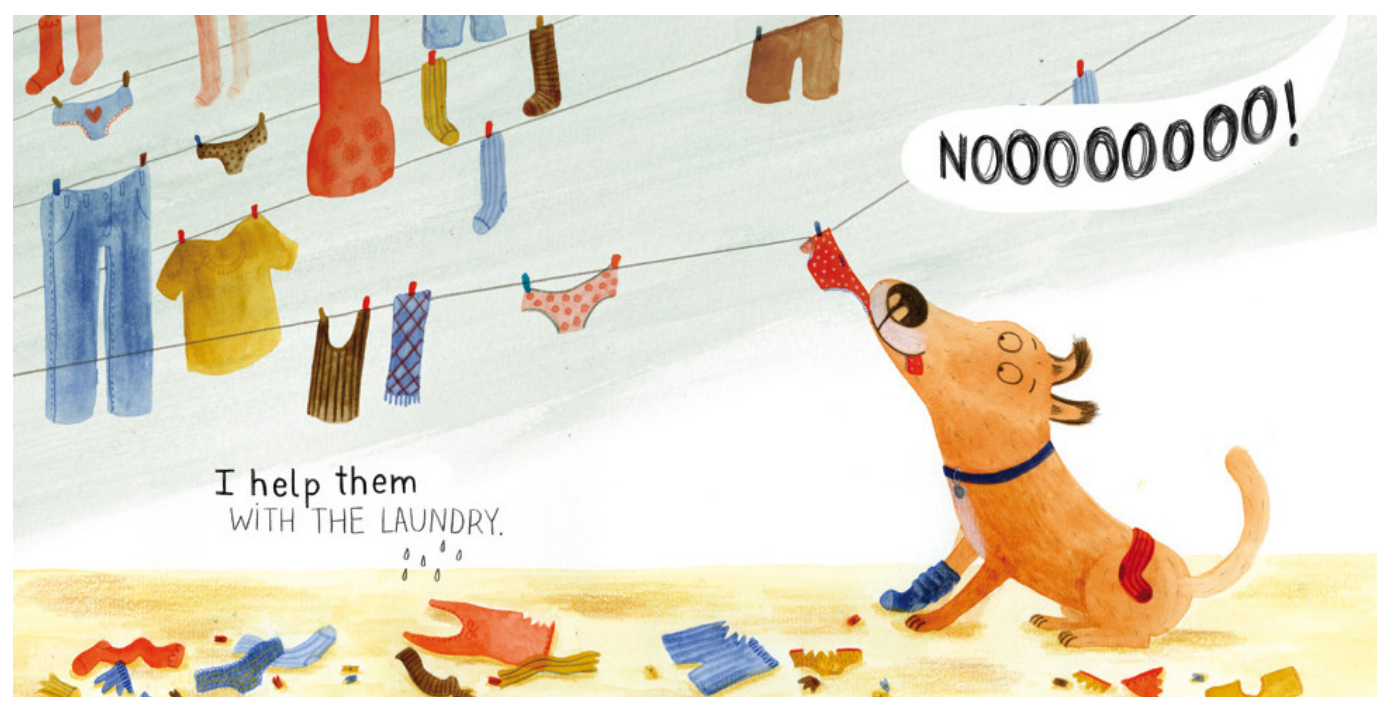

Fig.3. Marta Altés, No!, 2011. 
Crafting a believable character is imperative for the success of any picture book, especially because the majority of contemporary picture books are character-driven. However, creating such a character is a rather personal process for each artist, and therefore it varies somewhat from one illustrator to another.

First of all, the character should be based on the text of the narrative and generically recognisable characteristics. Getting to know the character thoroughly is therefore the best place to start. While some specifications come usually from the narrative itself, the rest is based on research. The research can provide the illustrator with both general identifiable features and delicate details of any animal or human that the artist can then apply to his/her drawings, making the characters accurate and instantly recognisable for the reader as a specific animal species or human being. While Will Terry states that those features of a cat such as pointy ears, eyes, whiskers, triangular nose, and wiggly tail applied on any shape will be deciphered by a reader as a cat, Lynne Chapman adds that it is a fine simplification and exaggeration of those features that in fact shapes the character, so "it looks real, it looks like a cat, but actually no, it's not. It's got this other picture book quality to it" (Will Terry, 2011; Open College of the Arts, 2011). Moreover, by making and adhering to general lists of physical appearance, personalities, abilities, and habits of their characters, illustrators safeguard the continuity of visual appearance of characters through the whole book.

Illustrators also often work with stereotypes. Martin Ursell (2013, p. 49) claims that "stereotypes are useful, essential even, in communicating character" for they present the reader with something instantly known to him/her. The artist, however, should build on stereotypes rather than make universal illustrations, for those would lack any diverse personality; a feature essential to any picture book's character. Furthermore, stereotypes often present only a single viewpoint which leads to failure of the book in the sense of broadening the children's horizons and encouraging their ability to form a more complex understanding of a story, topic, or people (Adichie, 2009). For that reason, stereotypes should be used wisely and only serve as a base to add the distinctive personality of the character that comes always from the particular story.

As for the character's gender preference, it has a tendency to cycle. While a study from 2011 revealed male characters outnumbering female in picture books, some illustrators that were interviewed stated that about 20 years ago, the situation was reversed and there was a significant push for including more male characters into picture books to encourage boys to read more (Flood, 2011; Sloat, 2013; Lies, 2013). While the lion's share of picture books nowadays are written clearly with one or the other gender of the character in mind, there are some gender-neutral manuscripts that leave the decision up to the illustrator. The attitude of illustrators to this topic is threefold. Firstly, there appears to be a double standard, for girls will gladly read books with male characters, but boys do not as eagerly read 'girl' books (Open College of the Arts, 2011; Murguia, 2013; Dewdney, 2013). For that reason, many illustrators would pick a boy to be their leading character, as Lynne Chapman did, for instance, in Julia Jarman's picture book Bears on the Stairs (Open College of the Arts, 2011).

Tom Lichtenheld has a completely different approach to this matter. He tries to break the general assumptions and prejudice of a need to have a male in the role of the main character. "For instance, when I'm reading to kids and come across a character of unspecified gender, I'll make it a female. I can actually detect a little hiccup in the children's understanding of the character because they assume it will be a male. I've even had kids protest that it should be a boy. Go figure" (Lichtenheld, 2013). 
Secondly, the decision of the illustrator regarding the gender of a character can be influenced by personal reasons. There is an increased inclination to put one or the other gender as a main character based on the illustrator's own family background, especially the gender of the illustrator's own children. Other reasons can be purely artistic. Christine Tripp (2013) for instance, would probably draw a girl, because she loves "detail and quirkiness, and find both hairstyles and clothing can be manipulated by me, to a greater extent, with a girl than with a boy".

Many illustrators indicated that their decision would be based on the story itself, depending on the subject matter, action, setting, plot, and genders of the other characters in the narrative (Finn, 2013; Lies, 2013; Waites, 2013; Downing, 2013; Meidell, 2013). While Brian Lies (2013) adds that he likes to "listen for clues in the text - did the author IMPLY a boy or a girl?", Ann Marie Finn (2013) contributes with a great example of this advice in use, "I used a girl as the main character as it was about someone who despaired of their hair, so it made sense to have a girl for that".

\section{LAYOUT}

There are a few elements related to the layout that can enhance or diminish the reader's experience. Therefore, it is essential to keep them in mind and find a good solution for each publication to give it its best chance to succeed. To start with, many picture books work with full spread illustrations and therefore, a bleed ${ }^{1}$ and a gutter ${ }^{2}$ must be taken into account at all times. No important parts of the illustration should be placed near the gutter or too close to the bleed to prevent unwanted cropping or disruption in the image. According to Christine Tripp (2013), it is quite a common mistake even for the most experienced illustrators to do, because both pages of each full spread illustration are done as one continuing artwork and it is easy to get consumed by one's enthusiasm. If the illustrator happens to forget about the bleed and gutter, the illustration must be redone.

\section{Secondly, a distance from the gutter and the bleed line must be always kept when dealing with the text to ensure the reader can go through the book without any disturbance, and while it is rarely the illustrator's duty to deal with the text itself, it is usually his/her responsibility to leave enough space for the text in the layout of the artwork.}

In that sense, the illustrator must respect the gutter and the bleed limitations as well as the responsible graphic designer. To make sure that the block of text "will not overlap an important element of the illustration ... and the illustration will not interfere with the viewing and readability of the text", the illustrator needs to create an unoccupied zone within the artwork big enough to place the text into (Tripp, 2013). The right size of such an area can be calculated by using a dummy spread with text in correct size and font provided by the publisher. Lynne Chapman, for instance, likes to get such dummy spreads for each book she is working on, for it allows her to judge the space easily, even though the text's placement is not yet accurate (ShooRaynerLife, 2011).

${ }^{1}$ A bleed - an overlapping area that is cropped off in the process of binding

${ }^{2} \mathrm{~A}$ gutter - line where two pages are bound together 
Establishing a natural, engaging flow of the narrative's story is imperative for the success of a picture book and its ability to be beneficial to children. The flow can be affected by many factors, such as the verbal pace of the narrative, division of the text, layout, composition of each page, and interaction of text and images. While the verbal pace is established by the author, the text division is done either by the editor or illustrator and is connected closely to a choice of a particular section of the text that is to be interpreted visually by the artist.

While there is no instant recipe for the right text division, there are some issues both the editor and the illustrator should have in mind. As it was already mentioned, it is the author's responsibility to lead the reader through the action. Illustrations, on the other hand, should engage the reader's imagination and stimulate emotional responses while leaving enough space for the reader's own interpretation of the text. A shadowy figure, a set of eyes glowing in the darkness, empty rooms, or busy scenes can be much more powerful than a simple visual depiction of the action already communicated through the author's writing. For that reason, it is often beneficial to leave the illustrator free hand in picking the text to illustrate and it is also preferable by the majority of illustrators who welcome this challenge (Salisbury, 2004, pp. 96-97; Creative Choices, 2009).

The paramount purpose of the pacing is to engage the reader and encourage him/her to turn to the next page and the next page until the entire book has been read. "The urge to turn the page can be weakened if images or spreads feel repetitive in terms of shape, colour, or scale. Each spread must be designed with its relationship to the preceding and following pages in mind, and indeed its relationship to the flow of the book as a whole" (Salisbury, 2004, p. 83). The layout of elements on the individual pages naturally adds greatly to this effort; nevertheless, it is the interaction of the text and the image in relation with each other or a composition of the parts of the illustration itself. Orientation of action or actions occurring in the illustration is also often taken into account. This can be related both to the movement of the leading character or other parts of the illustration. For instance, a character positioned in the lower left-hand corner of the spread running toward the edge would motivate the reader to find out what the character is running towards and subsequently initiate a page turn (Nikolajeva and Scott, 2006, p. 152).

Likewise, a variety of angles, viewpoints, orientation of action, and composition can complement the pacing of the book and influence a feeling and drama that comes from the narrative. The pace is usually established on a storyboard that is made of small thumbnails of all 32 pages $^{3}$ of the picture book. However, only about 24 pages are usually dedicated to the story itself. The remaining pages are used for endpapers, a title page, a copyright page, a dedication, and in some cases, a right-hand first page and left-hand last page of the story. An example of a storyboard (Figure 4) for A Tale of Two Penguins picture book shows both the story division on spreads and pacing that is, as usual, developed through thumbnail sketches, for it is friendly to making any changes in a small amount of time. A variety of cropping, viewpoints, and layouts were used to communicate emotions, add drama, and bring a change of pace. A graphic element of borders around smaller images was used to add a partition firstly and eventually interaction between pages and the image itself later on. A lonely figure of a penguin framed inside the border of left page of the second spread is in strong contrast with the opposite page full of penguins having fun and communicates a different approach of the two main characters to the life and celebrations. The movement is mostly oriented from left to right, encouraging the reader to move forward, and is only reversed on two spreads where such a break of the established pattern was in tune with the action within the story. Endpapers were used to add to the narrative; for example, the back endpaper picturing the arrival of a package with a gift to a human home, while the story ends by the penguins sending the packages out on the last spread of the book.

${ }^{3}$ A majority of picture books are 32 pages long. The reason for that can be traced to the printing process. If the publication is longer or shorter, it is always by 8 more/less pages. 

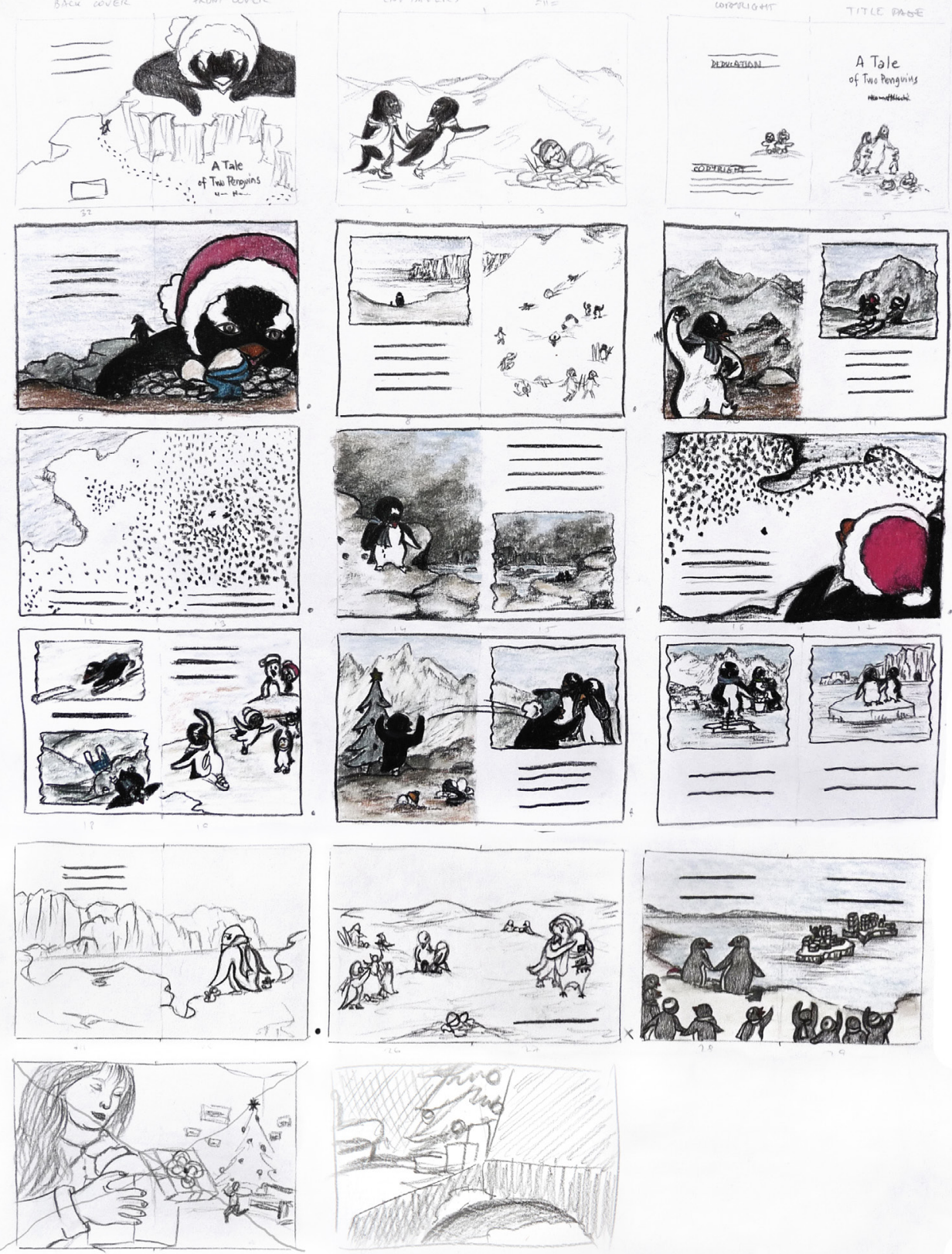

Fig.4. Hana Hladíková, A Tale of Two Penguins Storyboard, 2014.

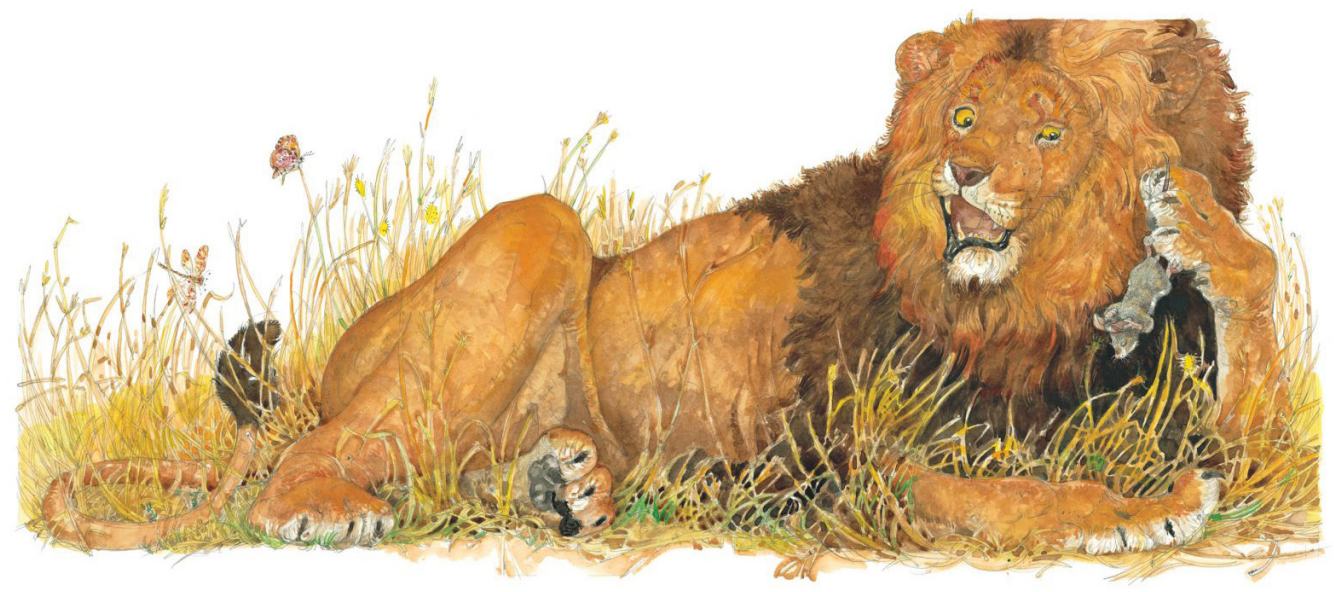

Top: Fig.5. Jerry Pickney, The Lion and the Mouse, 2009. 


\section{COLOUR CHOICES AND STYLE}

Although the colour palette greatly affects the overall feeling of a picture book conveyed to the reader, its selection, even though based on what the story needs, seems to be an intuitive process for a majority of illustrators. Many times, there are a limited number of colours repeatedly occurring through the whole book, with the rest complementing them (Finn, 2013). This approach provides a continuity and feeling of wholeness within the book. Nevertheless, the utmost purpose of the colour is the creation of a mood. The mood can be triggered by many sources. Colours often convey the emotional load of the picture, "such as paintings done in tones of grey to express dreariness/unhappiness" (Lies, 2013).

A set of colours can be also picked to complement the setting of the story, or its theme, as Teri Sloat (2013) has done in her picture book, I'm a Duck, where she worked with "springtime colours" of pastels, or the use of yellows and browns in Jerry Pickney's book, The Lion and the Mouse (Figure 5) (Meidell, 2013). In some cases, colours are used to communicate the time of day, different seasons, or for establishing an area of focus within the illustration. Other times, colours are picked to create enough contrast within the picture. For instance, if the character is dressed in blue jeans and the story calls for a sofa the character is to sit on, the colour of the sofa should not be blue also.

\section{IMPORTANCE OF COOPERATION WITH AN ART DIRECTOR, EDITOR...}

Producing a picture book is a long process involving many people on different positions working as a team. Because of its very competitive market, only the best work can be accepted and "a skillful art director can bring out the best in an illustrator" (Tripp, 2013) by providing another educated opinion on the artwork. Art directors are also equipped with "different set of experience when it comes to viewing art so they can add from there great depth of expertise" (Meidell, 2013).

All illustrators stated that their cooperation with the art director is a critical part of their process. As it was already mentioned, the job of the art director starts even before the illustrator is chosen, and continues through the whole time of the book creation after the cooperation with the selected illustrator is confirmed. Art directors approve the route the illustrator is taking in different stages of the illustrating process, from sketches of characters, through storyboards, and rough sketches, to the final artwork, which gives the illustrator a sense of security that his/her final artwork will be accepted. In addition, the art director encourages the illustrator to produce the best artwork possible by providing helpful suggestions for changes, corrections and additions in the artwork, honest comments throughout the whole process, and any other support the illustrator needs.

\section{CONCLUSION}

Producing quality literature for young children is an enormous responsibility. Illustrators have a great impact on the ability of picture books to function correctly and succeed on the competitive market. An ultimate intention of this thesis was to determine the complexity of a picture book illustrator's job, point out elements that help the illustrator to produce an engaging, successful art and illustrate the importance of picture books for children on their journey to grow up as complex human beings. Thanks to excellent guidance and comments of illustrators interviewed there is a lot to learn and take inspiration from. 


\section{ACKNOWLEDGEMENTS}

This paper would have not been possible to complete without the assistance from all of my interviewees, talented children's book illustrators who were so kind to answer my questions and supported me with their kindness as well as their knowledge. A big thank you also belongs to my advisor, Leah Adler, for her guidance and never-ending optimism. In addition, I would really like to thank to my parents for aiding me with their love and patience.

\section{REFERENCES}

Adichie, Ch. (2009) 'Chimamanda Adichie: Danger of Single Story', TED. Available at: http://www.ted.com/talks/ chimamanda_adichie_the_danger_of_a_single_story.html (Accessed: 22 January 2014).

AlbanKALB (2013) Brown Bag Lunch Speaker's Forum: The Making of a Picture Book. Available at: http:/ /www.youtube. com/watch?v=C8qclTXYnC0 (Accessed: 22 October 2013).

Bosman, J. (2010) 'Picture Books No Longer a Staple for Children', New York Times, 7 October [Online]. Available at: http://www.nytimes.com/2010/10/08/us/08picture.html?_r=4erpagewanted=1er (Accessed: 7 October 2013).

Creative Choices (2009) Helen Craig: Book Illustrator. Available at: http://www.youtube.com/watch?v=cFeBM4h49LE (Accessed: 29 October 2013).

Dils, T. E. (2009) You Can Write Children's Books. 2nd edn. Cincinnati: Writer's Digest Books.

Flood, A. (2011) 'Study finds huge gender imbalance in children's literature', theguardian, 6 May [Online]. Available at: http://www.theguardian.com/books/2011/may/06/gender-imbalance-children-s-literature (Accessed: 12 October 2013).

Hladíková, H. (2013) Questionnaire - answers by Ann Dewdney, 22 October 2013.

Hladíková, H. (2013) Questionnaire - answers by Ann Marie Finn, 4 November 2013.

Hladíková, H. (2013) Questionnaire - answers by Bethanie Murguia, 5 November 2013.

Hladíková, H. (2013) Questionnaire - answers by Brian Lies, 19 November 2013.

Hladíková, H. (2013) Questionnaire - answers by Christine Tripp, 21 October 2013.

Hladíková, H. (2013) Questionnaire - answers by Joan Waites, 12 November 2013.

Hladíková, H. (2013) Questionnaire - answers by Julie Downing, 9 November 2013.

Hladíková, H. (2013) Questionnaire - answers by Sherry Meidell, 28 October 2013.

Hladíková, H. (2013) Questionnaire - answers by Teri Sloat, 24 October 2013.

Hladíková, H. (2013) Questionnaire - answers by Tom Lichtenheld, 18 November 2013.

IllustrationCourse (2011) Children's book illustrator Patrice Barton on her art for "Mine!" by Shutta Crum. Available at: http:/ / www.youtube.com/watch?v=Gq8ip_7nrds (Accessed: 18 October 2013)

Kiefer, B. Z. (2009) Charlotte Huck's Children's Literature. 10th edn. Boston: MCGRAW-HILL Higher Education. LibraryOfCongress (2010) Anita Silvey: 2010 National Book Festival. Available at: http://www.youtube.com/ watch?v=1Fe0gQrVyFl (Accessed: 20 October 2013).

Nikolejeva, M. and Scott, C. (2006) How Picturebooks Work. London: Taylor e Francis Ltd.

Northrup, M. (2012) Picture books for children: Fiction, folktales and poetry. ebrary Prague College [Online]. Available at: http://site.ebrary.com/lib/pcollege/docDetail.action?doclD=10635885erp00=draw+illustration (Accessed: 25.10.2013)

Open College of the Arts (2011) How to Illustrate a book - part 1. Available at: http:/ /www.youtube.com/ watch?v=LKIME1rGoy4 (Accessed: 27 October 2013).

Paul, A. W. (2009) Writing Picture Books. Cincinnati: Writer's Digest Books.

Pierce, T. (2010) 'Five Reasons Why Children NEED Picture Books', Terry Pierce: Children's Author, 12 October. Available at: http://terrypierce.blogspot.cz/2010/10/five-reasons-why-children-need-picture.html (Accessed: 11 October 2013). 
Reading Is Fundamental (2010) CHOOSING GOOD BOOKS: Getting the Most Out of Picture Books. Available at: http:// www.rif.org/us/literacy-resources/articles/getting-the-most-out-of-picture-books.htm (Accessed: 17 October).

Revolution21 (2013) BBC - The Beauty of Books. Part 3: Illustrated Wonderlands. Available at: http://www.youtube.com/ watch?v=pVso9sEt31M (Accessed: 12 November 2013)

Salisbury, M. (2004) Illustrating Children's Books. New York: Barron's Educational Series, Inc.

ShooRaynerLife (2011) Illustrating books with Lynne Chapman. Available at: http:/ /www.youtube.com /

watch?v=rqUiaRCE3ao (Accessed: 18 October 2013).

Ursell, M. (2013) Illustrating Children's Books. Ramsbury, Marlborough: The Crowood Press Ltd.

Will Terry (2011) Drawing Characters - „How To Illustrate Children's Books" - 7videos-. Available at: http:/ /www.youtube. com/watch?v=dWxdLNLKJvk (Accessed: 10 October 2013).

IMAGE LIST

FIGURE 1: Chapman, L. (2010) Bears on the Stairs. London: Andersen Press Ltd., pp. 14-15, illus.

FIGURE 2: Frazee, M. (2008) A Couple of Boys Have the Best Week Ever. [book illustration].[Online]. Available at: http://www.amazon.com/Couple-Boys-Have-Best-Week/dp/0152060200/ref=sr_1_12?s=bookserie=UTF8erqid= 1392110131ersr=1-12erkeywords=frazee+marla (Accessed: 26 November 2013).

FIGURE 3: Altes, M. (2011) No! [book illustration].[Online]. Available at: http://www.martaltes.com/No (Accessed: 20 October 2013).

FIGURE 4: Hladíková, H. (2013) A Tale of Two Penguins [storyboard].

FIGURE 5: Pinkney, J. (2009) The Lion and the Mouse [book illustration]. [Online]. Available at: http:/ /www.lexpublib. org/page/2009-best-picture-books (Accessed: 3 December 2013). 